\title{
26
}

Subdirección General de Estudios y Evaluación de Instrumentos de Politica Comercial*

\section{RECUPERACIÓN ECONÓMICA Y PROBLEMAS DE ABASTECIMIENTO: EL PAPEL DE LOS FLETES}

El comercio internacional ha desempeñado un papel clave durante la pandemia. Sin embargo, la crisis sanitaria y la posterior reactivación también han puesto de manifiesto vulnerabilidades en las cadenas globales de suministro, dando lugar a fenómenos recurrentes de escasez que podrían poner en riesgo la sostenibilidad de la recuperación económica. Entre estas vulnerabilidades destacan los cuellos de botella relacionados con el transporte marítimo de mercancías contenerizadas, que se están reflejando en fuertes aumentos de los precios de los fletes. En este trabajo se analizan los problemas de abastecimiento que se han registrado, tanto durante la fase más contractiva de la pandemia como a partir de la recuperación. Se analiza especialmente el caso del transporte marítimo que, por su naturaleza horizontal, puede afectar a una amplia gama de industrias, y se exploran algunas de las implicaciones para las estrategias de las empresas, para el sector de transporte marítimo y para el diseño de las políticas comerciales.

Palabras clave: comercio internacional, transporte marítimo, contenedores, cuellos de botella. Clasificación JEL: F10, F13, F14, R40, R41.

\section{Introducción}

Entre las lecciones aprendidas de la crisis desencadenada por la pandemia COVID-19, la preocupación por la resiliencia de las cadenas globales de suministro es una de las más destacadas.

El comercio internacional y las cadenas globales de valor sobre las que se organiza han desempeñado un papel clave durante la

\footnotetext{
* Secretaría de Estado de Comercio.

Versión de noviembre de 2021.

DOI: https://doi.org/10.32796/bice.2021.3141.7326
}

pandemia. Además de proporcionar mercados a nuestras empresas cuando la demanda interna se mostraba más débil, el comercio internacional ha sido esencial para poder acceder a los productos necesarios para combatir la COVID-19 y proteger la salud de los ciudadanos. Sin comercio exterior, no habríamos podido adquirir equipos médicos ni mascarillas. Tampoco habría sido viable el desarrollo de vacunas en un tiempo récord y su distribución a nivel internacional, que han sido vitales para contener la pandemia. En la fase de recuperación, el comercio internacional está también siendo clave para la reactivación de las economías. 
La preocupación en torno a las cadenas globales de suministro se centró, en la fase más álgida de la crisis sanitaria, en el abastecimiento de material farmacéutico y sanitario, aprovisionamientos estratégicos para combatir la pandemia. En la fase de recuperación, son las tensiones para el suministro de una amplia variedad de bienes, cuya escasez podría lastrar la recuperación de la producción y de la actividad económica, las que suscitan mayor preocupación. Entre estos bienes destacan algunas materias primas y productos intermedios manufacturados.

Una de las razones por las que se están produciendo estas tensiones son las dificultades logísticas que han aflorado en este periodo $y$, en concreto, las asociadas al transporte marítimo de productos manufacturados. El transporte contenerizado, en particular, juega un papel fundamental en el comercio internacional de estos productos y su coste ha experimentado un fuerte crecimiento, al tiempo que se han reducido la fiabilidad y la regularidad de los suministros.

En este trabajo se analiza, en primer lugar, el impacto de la pandemia en la economía y el comercio mundiales. Se estudian, a continuación, los problemas de abastecimiento que se están registrando en la actual fase de recuperación. En los siguientes epígrafes se analizan los cuellos de botella que, tanto durante la crisis como en la posterior recuperación, generaron estos problemas. A continuación se centra la atención en uno de los factores determinantes de esta tensión: el transporte marítimo y, en particular, las dificultades y el aumento de costes que está experimentando el transporte contenerizado de mercancías. Se estudian también las causas, algunas coyunturales y otras de naturaleza más estructural, que subyacen a esta evolución. Finalmente, se exploran algunas implicaciones para las estrategias de las empresas, del propio sector de transporte marítimo internacional, y en la orientación de la política comercial y otras políticas públicas.

\section{El impacto de la pandemia en la economía y el comercio mundiales}

La pandemia COVID-19 supuso una inesperada disrupción en la economía y en el comercio internacional. Su impacto extremo y su carácter de suceso extraordinario e impredecible permiten calificarla como lo que Taleb (2007) ${ }^{1}$ denominó un «cisne negro».

Así, como puede apreciarse en el Gráfico 1, durante el año 2020, la crisis sanitaria tuvo un impacto acusado en la actividad económica mundial y aún más intenso en el comercio internacional de bienes y servicios. Sin embargo, el efecto en los flujos internacionales de bienes fue más moderado que el registrado en servicios. Además, para el conjunto del año 2021 las previsiones apuntan a una recuperación del comercio internacional de bienes más acentuada que la del agregado de bienes y servicios y por encima del crecimiento que registrará el PIB mundial.

Esta evolución se explica, principalmente, por el elevado impacto que las medidas adoptadas como consecuencia de la crisis sanitaria tuvieron en la movilidad internacional de las personas, estrechamente vinculada con la provisión de determinados servicios, en particular, los relacionados con el turismo. En el caso de los bienes, en algunos sectores, como el $D$

El propio Taleb mantiene una posición más matizada sobre el tema. La pandemia podría no reunir la característica de imprevisibilidad, propia de un cisne negro, en la medida en que los especialistas eran conscientes de que este tipo de eventos podía ocurrir. Sin embargo, como señaló en un encuentro organizado por Aditya Birla Capital, lo que no es un cisne negro para la persona A puede serlo para la persona B. https://www.youtube. $\mathrm{com} /$ watch? $=\mathrm{r}$-jo5RpVva0 


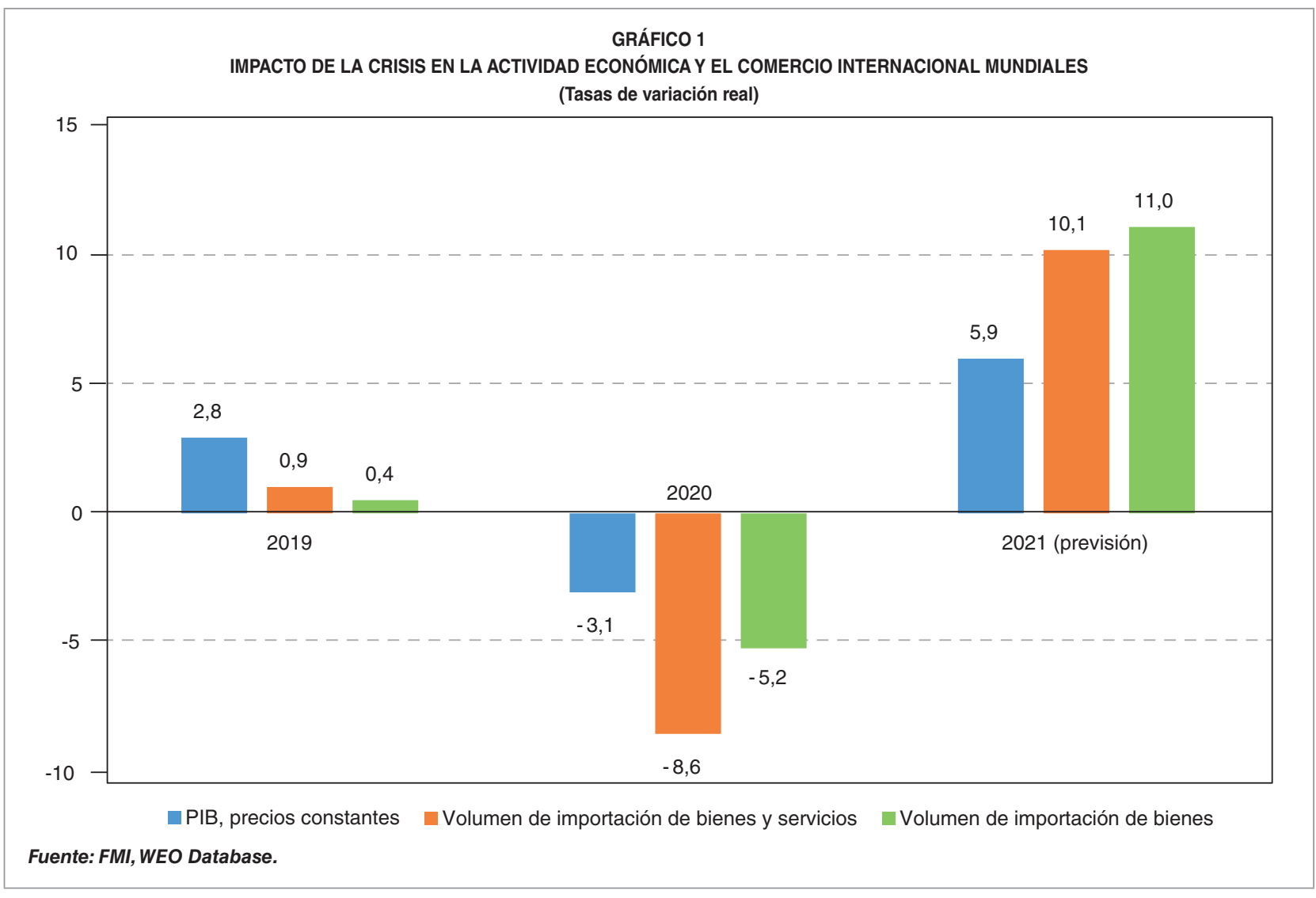

energético, se acusó también con intensidad el impacto de las restricciones a la movilidad. Sin embargo, en otros, el efecto de la pandemia sobre la oferta se vio, en cierta medida, atemperado por un desplazamiento de la demanda de los consumidores, como se expone en los siguientes epígrafes.

Además, la pandemia no se ha manifestado de forma simultánea en todas las economías, sino que ha tenido impactos geográficos asimétricos y asincrónicos. Las medidas de contención, primero, y el despliegue de las estrategias de vacunación y de medidas de reactivación económica, después, también han sido geográfica y temporalmente dispares. Ambas características han propiciado el afloramiento de vulnerabilidades, que hasta entonces habían pasado desapercibidas, en las cadenas de valor regionales y globales.

\section{Los problemas de abastecimiento en la fase de recuperación}

Las empresas perciben las tensiones en las cadenas de suministro como uno de los principales factores de riesgo que amenaza la evolución de la economía mundial. La escasez de algunos productos clave y los problemas más generalizados de suministro han ganado relevancia, desde que se inició la recuperación de la actividad, como factores que ponen en riesgo la capacidad de las empresas de continuar aumentando su producción. Esta percepción es generalizada en el conjunto de la Unión Europea (UE) y afecta a todos los sectores manufactureros.

De acuerdo con los resultados de la encuesta que anualmente realiza la consultora KPMG, el $12 \%$ de los directores ejecutivos $\triangleright$ 


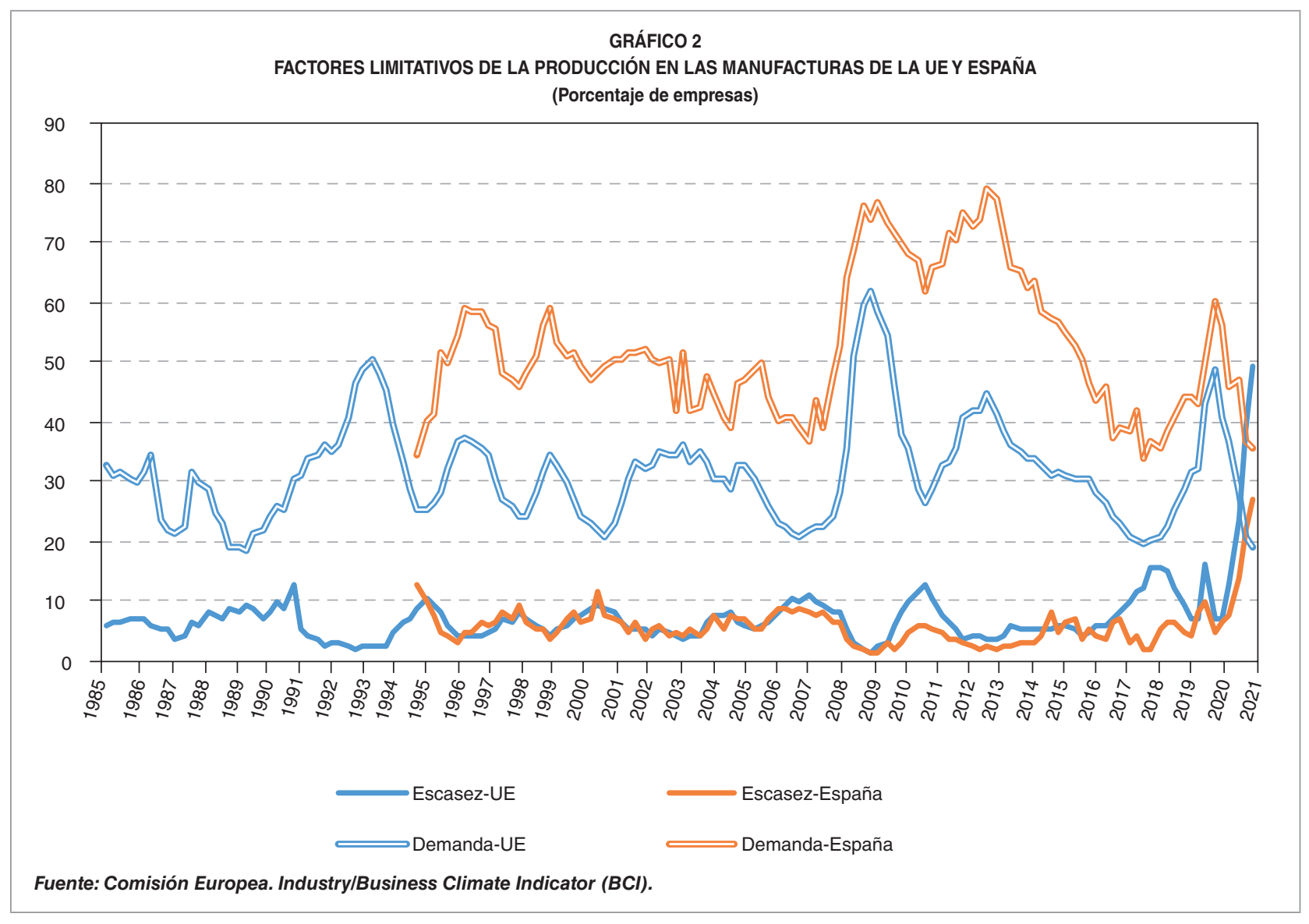

de las principales compañías internacionales ${ }^{2}$ señala a las cadenas de suministro, junto a la ciberseguridad y al cambio climático, como los principales riesgos que amenazan el crecimiento de sus empresas en los próximos tres años (KPMG, 2021).

En España, los directores ejecutivos sitúan el riesgo derivado de las cadenas de suministro en la quinta posición, por detrás de otros, como los asociados a las nuevas tecnologías, la ciberseguridad, el cambio climático y los riesgos operacionales. Sin embargo, el $64 \%$ de ellos reconoce tensiones en sus cadenas de suministro en el último año y medio, y en algunos sectores, como los de consumo, industria o automoción,

2 KPMG realizó la encuesta entre los meses de julio y agosto de 2021 y contó con la participación de 1.325 directores ejecutivos de grandes empresas de once países y once sectores. las cadenas de suministro se perciben como el principal factor de riesgo (KPMG, 2021).

Otras investigaciones sobre las percepciones empresariales confirman la importancia que ya están adquiriendo las dificultades de suministro como factores limitativos de la actividad económica. La Comisión Europea elabora un indicador de clima de negocios, referido a la industria manufacturera, sobre la base de encuestas armonizadas en los Estados miembros. Estas encuestas recogen, con periodicidad trimestral ${ }^{3}$, información sobre los factores que afectan o limitan la producción. En el cuarto trimestre de 2021, las empresas manufactureras de la UE han identificado la escasez de materiales o de equipo como el principal factor limitativo de la $D$

3 El dato del primer trimestre se recoge en el mes de enero, el del segundo, en abril; el del tercero, en julio; y el del cuarto, en octubre. 
producción. En concreto, en este trimestre, el $49,4 \%$ de las empresas manufactureras de la UE considera que la escasez de materiales o equipo limita su producción. Como se observa en el Gráfico 2, este es, con diferencia, el valor más elevado alcanzado por este indicador desde que se comenzaron a recoger datos sobre el mismo a mediados de los años ochenta.

En España, la situación no es muy diferente, si bien la incidencia sobre la producción está siendo aparentemente menos intensa. Aunque los empresarios de la industria manufacturera española identifican como principal factor limitativo de su producción la debilidad de la demanda (el factor que, tradicionalmente, tiene un mayor peso), la escasez de materiales o de equipamiento se eleva también a niveles máximos históricos. En concreto, el número de empresas que consideran que este está siendo un factor limitativo supera en $26,9 \%$ del total. Al igual que en el conjunto de la UE, es con diferencia el saldo de opiniones más elevado desde que, a mediados de los años noventa, comenzó a registrarse información sobre este factor (Gráfico 2).

Tanto en el conjunto de la UE como en España, el indicador de escasez había registrado un repunte en el segundo trimestre de 2020 , el periodo en el que se adoptaron medidas de contención más duras que afectaron a la capacidad de producción. Estas medidas afectaban tanto a los países de la UE como a algunos de sus proveedores, particularmente las economías asiáticas, así como a las capacidades $\triangleright$

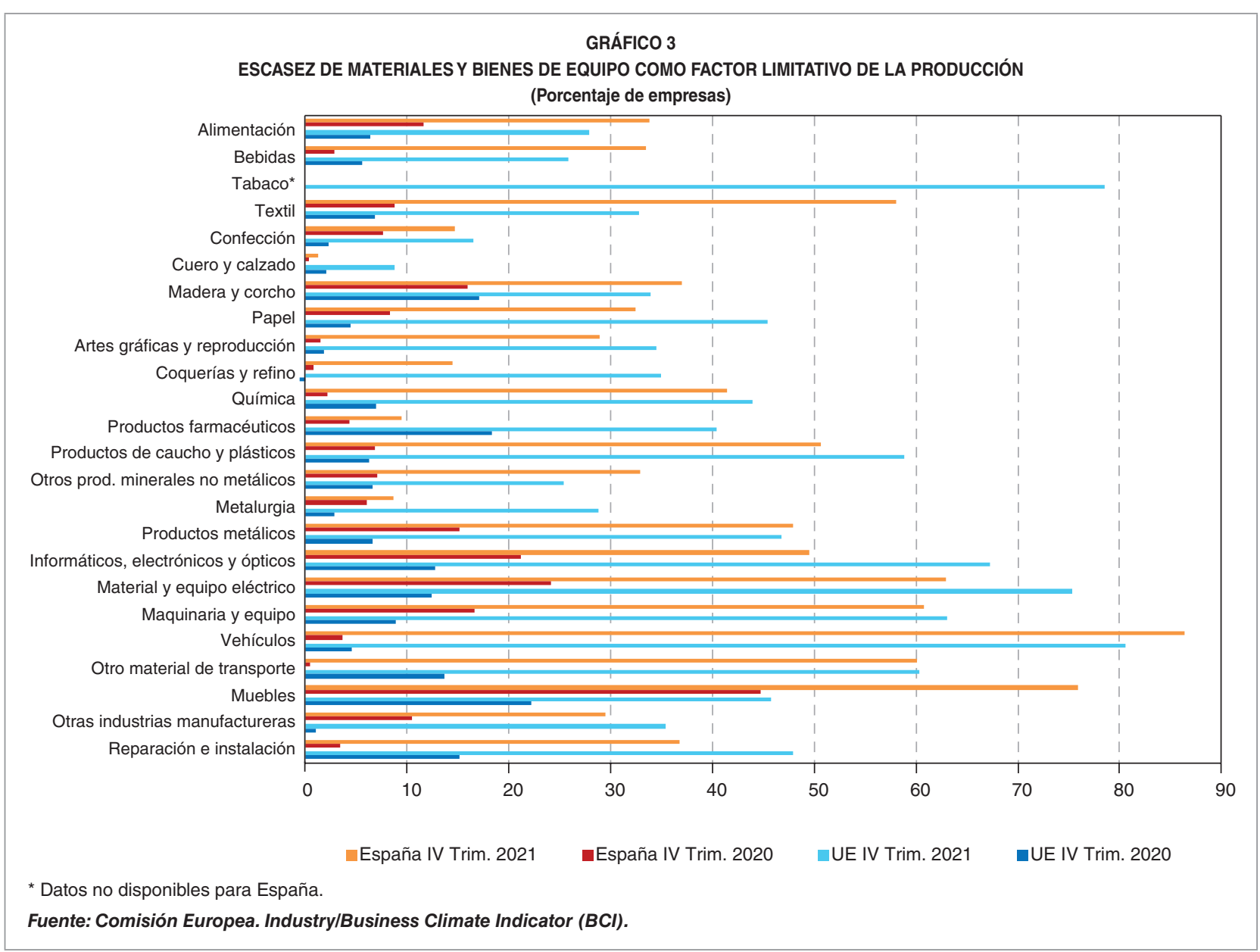




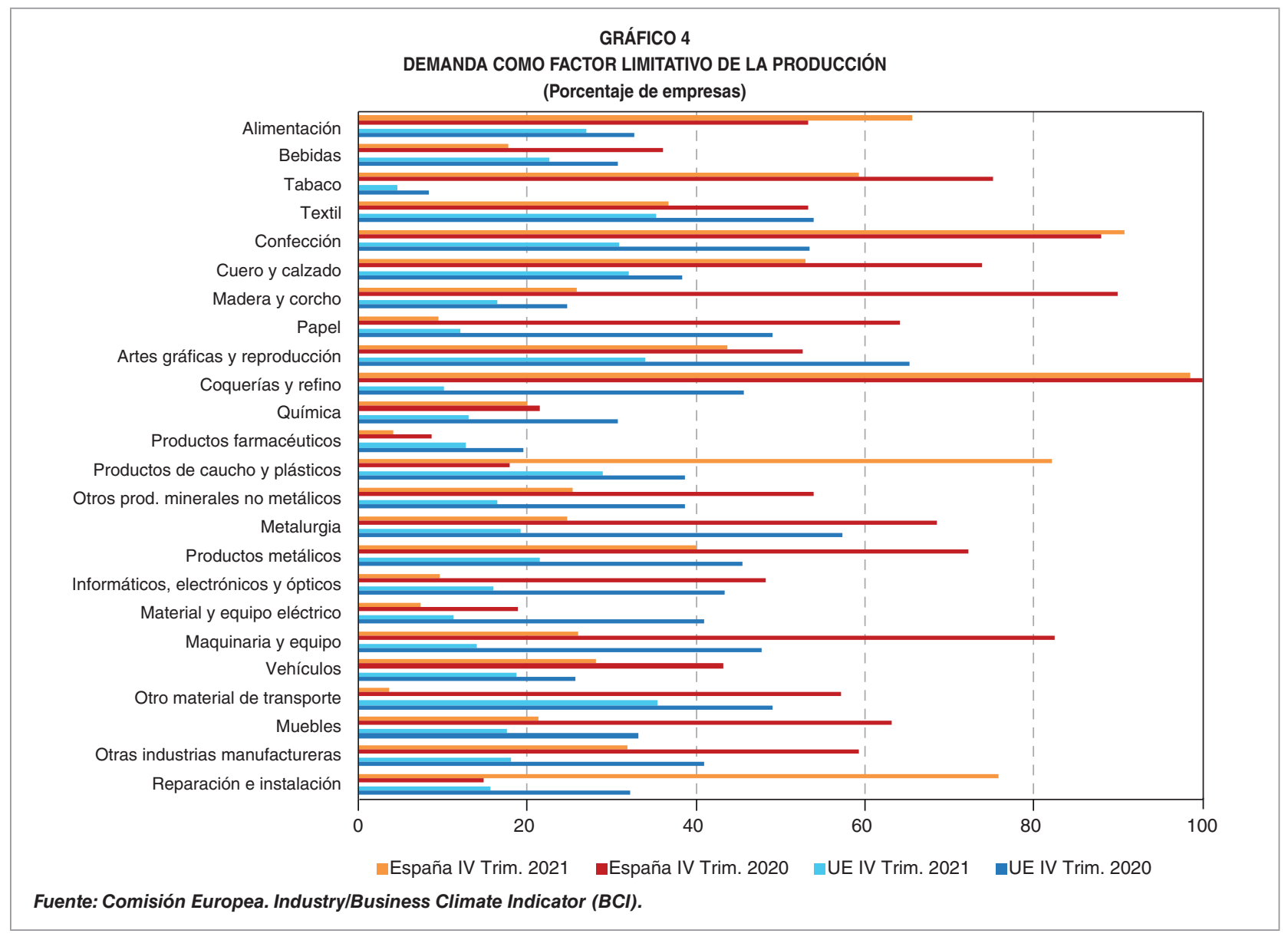

logísticas. Sin embargo, en la segunda mitad de 2020 el indicador retorna a niveles normales y no es hasta el primer trimestre de 2021 (el segundo trimestre, en el caso de España) cuando comienza a manifestarse una preocupación creciente por la escasez de materiales y equipos.

Esta preocupación coincide con una fase de recuperación de la demanda, que se refleja también en las percepciones empresariales. El indicador correspondiente se sitúa en niveles próximos a sus mínimos históricos, lo que muestra que, en esta fase, los empresarios no atribuyen a la demanda un carácter especialmente limitativo de su producción, en comparación con los niveles habituales.

La percepción de la escasez de materiales y bienes como un factor limitativo de la producción es sectorialmente generalizada, tanto en España como en el conjunto de la UE. Los Gráficos 3 y 4 ilustran cómo en todos los sectores manufactureros (definidos a nivel de dos dígitos de la CNAE) el indicador de escasez, en el cuarto trimestre de 2021, ha registrado niveles nítidamente más elevados que en el mismo trimestre del año anterior.

\section{Las disrupciones y cuellos de botella en las cadenas de suministro}

Los episodios de escasez registrados, tanto durante la fase de mayor impacto económico de la crisis sanitaria como en la actual recuperación, responden a una multiplicidad de factores que han afectado a las cadenas de $D$ 
suministro y se han propagado de unos sectores a otros. Las áreas de las cadenas de valor afectadas son múltiples (fabricación, suministro, logística y demanda, además de la propia población) y las vías de propagación de estos efectos no han sido siempre predecibles, sino que han respondido, en ocasiones, a vulnerabilidades inesperadas $u$ ocultas.

Los efectos de la propia expansión de la pandemia, de las medidas adoptadas para su contención y de los cambios inducidos en el comportamiento de los agentes económicos, se dejaron sentir en todos los eslabones de las cadenas de valor. Así, la capacidad de producción, la demanda y las infraestructuras y operaciones logísticas resultaron alteradas. Se generaron, además, efectos dominó al propagarse las disrupciones registradas en determinados eslabones de la cadena de valor a los restantes.

La rápida recuperación de la demanda mundial, a partir de la segunda mitad de 2020, ha ocasionado, a su vez, nuevos cuellos de botellas. No solo ha presionado al alza sobre el precio de las materias primas, sino que además ha dado lugar a problemas de abastecimientos en diversos sectores, entre los que pueden citarse los de semiconductores, productos químicos, plásticos, madera o metales de uso industrial (Kataryniuk, del Río Lopezosa y Sánchez Carretero, 2021).

El desabastecimiento de semiconductores ha sido, quizá, el caso que ha recibido mayor atención. El impacto que ha tenido este cuello de botella en la industria del automóvil contribuye al elevado nivel alcanzado por el indicador de escasez de materiales y equipos como factor limitativo de la producción. El 80,6\% de los fabricantes de la UE y el $86,4 \%$ de los españoles consideran que la escasez de materiales y equipos está limitando su capacidad de producir. Se trata, por tanto, de una percepción fuertemente consolidada en el sector.

El desabastecimiento de semiconductores se asocia a cambios en la composición de la demanda de los productos que los utilizan como insumo. Aunque la producción de automóviles se redujo fuertemente en el segundo trimestre de 2020, la mayor demanda de otros equipamientos electrónicos, asociada al mayor tiempo de permanencia en los hogares y al auge del teletrabajo, compensó el efecto del descenso de la producción de automóviles sobre la demanda de semiconductores. En consecuencia, el grado de utilización de la capacidad de producción en este sector se mantuvo en niveles altos. Cuando la demanda de automóviles se recuperó, no resultó posible aumentar la producción de estos insumos en la misma medida (Attinasi, Bobasu y Gerinovics, 2021).

La evidencia hasta ahora disponible muestra, en todo caso, cómo los problemas observados en las cadenas de suministro durante la pandemia responden a una multiplicidad de factores. Hald y Coslugeanu realizan una revisión de la literatura, académica y no académica, producida en el año 2020 y clasifican los efectos de la pandemia COVID-19 sobre las cadenas de suministro en cinco áreas: fabricación, suministro, logística, demanda y efectos de la pandemia en la población.

En el Recuadro 1 se resumen los principales hallazgos identificados en cada una de esas áreas. Puede observarse que algunos problemas, como los cierres de fábricas, los problemas logísticos o los cambios en la demanda, afectaron a diversos sectores y áreas geográficas de forma asíncrona. Se concluye también que los problemas iniciados en determinadas áreas o sectores acabaron por repercutir en otras, generando o agravando los cuellos de botella que aparecían en ellas. 


\section{RECUADRO 1 \\ EFECTOS DE LA PANDEMIA COVID-19 EN DISTINTAS ÁREAS DE LA CADENA DE VALOR}

Fabricación. Los cierres, iniciados a principios de 2020 en China para contener el virus, tuvieron efectos que se propagaron a las industrias de Europa y América del Norte, altamente dependientes de inputs producidos en China. La recuperación de la producción en China fue lenta y vino acompañada también de interrupciones en sus cadenas de producción domésticas y, en paralelo, del establecimiento de restricciones sanitarias también en las industrias europeas y americanas.

Suministro. La escasez afectó primero a las industrias occidentales, así como a las industrias asiáticas, dependientes de inputs producidos en China. A partir de marzo de 2020 se produce una cierta reversión del fenómeno: los industriales chinos comienzan a experimentar escasez de inputs suministrados desde Europa y América del Norte, donde las medidas sanitarias y las bajas médicas obligan a reducir ritmos de producción.

Logística. El transporte sufrió disrupciones en todos los sectores. Los cierres portuarios en China (donde se ubican siete de los diez principales puertos de contendores del mundo) dieron lugar a una abrupta caída del tráfico marítimo. Las medidas sanitarias adoptadas en los puertos redujeron su capacidad operativa y, en combinación con las interrupciones en la aceptación de suministros por parte de las industrias sujetas a restricciones, generaron saturación de las infraestructuras portuarias. Esta saturación impactó también en el transporte por carretera. La industria de transporte aéreo resultó profundamente afectada por las restricciones al movimiento de personas y los cierres de fronteras. El transporte de última milla se vio también alterado por un aumento de las compras online y de los requisitos sanitarios para la entrega. En todos los sectores, algunas pequeñas empresas tuvieron que abandonar el mercado, lo que supuso una reducción de la capacidad global.

Demanda. El efecto de la crisis sanitaria fue diferenciado por sectores. La literatura detecta incrementos de la demanda en productos sanitarios y otros considerados esenciales, entre ellos los alimentarios. El teletrabajo también favoreció incrementos en otros productos no esenciales, como los servicios de streaming, las bebidas y aperitivos de uso doméstico o los productos de limpieza. Por el contrario, las medidas de contención tuvieron un impacto directo en la reducción de demanda de determinados servicios (como los de entretenimiento o restauración) y de los bienes asociados a dichos servicios. Se detectan también cambios en los hábitos de los consumidores, con efectos en los días de compra, tipo de empaquetado, etc.

Población. El doble papel de las personas, como consumidoras y como trabajadoras, está en el origen de otras disrupciones. Como consumidoras, se identifican cambios en las pautas de consumo o en el canal de compra (privilegiando la compra online, con efectos que pueden resultar duraderos), ante los que los sectores productivos y las redes de distribución tienen una limitada capacidad de adaptación a corto plazo. Como trabajadoras, se detecta escasez asociada a las bajas por enfermedad o a las medidas de contención y un aumento de costes o reducción de productividad, vinculado a las medidas de protección. En algunos sectores la restricción a la movilidad internacional de trabajadores tiene un impacto especialmente negativo.

Fuente: Hald y Coslugeanu (2021).

\section{El área con repercusión más horizontal es} quizá la de logística y transporte. Los problemas de cierre de fábricas, falta de mano de obra especializada o cambios en la estructura de la demanda repercuten en las necesidades logísticas. A su vez, los cuellos de botella en las infraestructuras portuarias o el transporte por superficie iniciado desde los puertos afectan a suministro y fabricación.

El análisis individualizado y más pormenorizado de algunas de las cadenas de suministro de productos donde se detectaron problemas $\square$ 


\section{RECUADRO 2 \\ CUELLOS DE BOTELLA OCULTOS EN CADENAS DE SUMINISTRO DE ALGUNOS PRODUCTOS DE USO COMÚN EN EE. UU.}

Harina y levaduras para uso doméstico. Se registró un incremento inesperado de la demanda doméstica en marzo de 2020, que podría explicar la escasez a corto plazo. La prolongación de esta escasez, sin impacto en productos industriales que emplean levaduras y harinas, se relaciona con el cambio de la demanda del segmento profesional al doméstico. Cada uno de estos segmentos tiene distintas necesidades de producción (levaduras frescas, frente a levaduras secas), de empaquetamiento (grandes paquetes industriales, frente a pequeños paquetes domésticos) y logísticas (en particular, para cubrir la última milla hacia el consumidor doméstico). Estos problemas se combinan con los plazos exigidos para la producción (fermentación de las levaduras) y con la falta de flexibilidad para adaptarse al cambio, acentuada por la escasez de mano de obra cualificada que exigen algunos de los procesos más automatizados.

Papel higiénico. Su demanda es altamente predecible y las cadenas de suministro son esencialmente regionales, dada la baja relación entre el valor del producto y los costes de transporte y almacenamiento. No hay dependencia de insumos importados. Más allá del efecto que pueda atribuirse a un comportamiento acaparador, supuestamente irracional, de los consumidores, que podría dar lugar a un incremento transitorio de la demanda, la escasez respondió a otros factores. Los confinamientos y el teletrabajo dan lugar a un cambio en la demanda, desde el segmento comercial (edificios de oficinas, industrias, aeropuertos, estadios, centros educativos, etc.) al doméstico. El tamaño de los rollos, la calidad exigida al producto y, sobre todo, el empaquetado (en pallets industriales o en paquetes de varios rollos) y las necesidades logísticas son distintas en ambos segmentos. Reasignar capacidad requiere inversiones costosas que las empresas no acometen, salvo que perciban que el cambio de comportamiento es duradero.

Toallitas y desinfectantes. La demanda registró un incremento notable que pronto agotó los inventarios acumulados por la industria. Otros sectores, como las destilerías o la cosmética, tienen capacidad para producir desinfectantes o toallitas, si cuentan con los elementos químicos básicos. Sin embargo, se subestimó la elevada dependencia de su importación desde China. El problema se agravó por la existencia de aranceles a las importaciones, la prioridad que los proveedores chinos otorgaron al suministro doméstico y las restricciones logísticas. La reacción de los grandes distribuidores minoristas fue inflar los pedidos para tratar de acaparar mayor cantidad de producto. Este comportamiento generó un «efecto látigo»: la industria aumentó su capacidad y, cuando se resolvió el problema de falta de materias primas, a principios de 2021, los minoristas se encontraron con un exceso de inventarios y debieron recurrir a ofertas para reducirlos, deprimiendo los precios.

Bandejas de pollo, cerdo y ternera. Las cadenas de suministro de estos productos están altamente concentradas en cuatro grandes empresas que aprovechan eficientemente las economías de escala. La pandemia tuvo un impacto elevado en la mano de obra del sector, afectada por la enfermedad y las obligaciones de cuarentena. Los paquetes preparados para el consumo doméstico son especialmente intensivos en trabajo, ya que requieren más acciones de corte, preparado, envasado y etiquetado. Su distribución también es más compleja. En condiciones de capacidad reducida, el suministro se centró en los productos que ofrecían mayor margen por hora de trabajo. El aumento de precios para los productos destinados al consumo doméstico más comunes no fue suficiente, en un contexto de suspensión de empleos y elevación del paro, para incentivar una reorientación de la cadena de suministro a este segmento. El cuello de botella en los eslabones intermedios generó, aguas abajo, escasez y aumento de precios y, aguas arriba, en el sector ganadero, un exceso de oferta que resultó en pérdidas y sacrificios de animales a destiempo.

Fuente: Kouvelis, 2021. 
de escasez muestra cómo las vías de propagación son diversas e incluyen algunas que, ex ante, no resultaban evidentes. En el Recuadro 2 se resumen algunos de los problemas detectados, para el caso de EE. UU., en productos de uso común. Es destacable que para algunos de estos productos se registraron, quizá por razones similares, problemas de escasez en otros mercados geográficos, incluso en los casos en que las cadenas de suministro son regionales o nacionales.

Entre las vías inesperadas de propagación cabe destacar los cambios de demanda entre distintos segmentos del mercado, la planificación aislada de la demanda, la aparición de cuellos de botella en recursos compartidos por los productores del sector, como el transporte y la distribución, y una estructura de las cadenas de suministro diseñada para maximizar la eficiencia que no resultó adecuada para un entorno de riesgo. Estos riesgos ocultos han resultado, al menos en algunos casos, tanto o más relevantes que los factores que, a priori, podrían parecer más influyentes, como los aumentos de la demanda, la dificultad para predecirlos, el acaparamiento por parte de los consumidores, los cierres de fábricas, la dependencia de importaciones de China, las cadenas de valor débiles, los aranceles o los cambios regulatorios (Kouvelis, 2021).

\section{Las restricciones en el transporte marítimo de mercancías: el precio de los fletes}

Los cuellos de botella en el transporte marítimo de mercancías podrían ser una de las principales causas de la percepción generalizada, en la UE y en España, de que la escasez de materiales y de bienes de equipo es actualmente el principal factor limitativo de la producción en la industria manufacturera. El precio de los fletes marítimos, en particular del transporte contenerizado, ha experimentado una fuerte alza coincidiendo con el repunte de la actividad económica y el comercio internacional. Esta evolución refleja el impacto de la pandemia, tanto sobre las pautas de consumo, que condicionan la demanda de transporte contenerizado, como sobre la capacidad del sector (en particular, por su incidencia en la operativa portuaria). Además, algunos rasgos estructurales, como el tamaño de los buques, los requerimientos de infraestructuras o la concentración en grandes alianzas, inciden en la respuesta de la oferta a cambios en la demanda.

Los hallazgos de la literatura recogidos en el epígrafe anterior revelan múltiples problemas puntuales que pueden incidir en un sector concreto y, al menos en algunos casos, dar lugar a un efecto dominó sobre otros. No obstante, también permite identificar algunas restricciones de carácter más horizontal, relacionadas con insumos o servicios compartidos por múltiples sectores.

Entre ellas destacan las vinculadas con la logística y el transporte marítimo de mercancías, que han sido especialmente señalados entre los causantes de los episodios de escasez observados durante la contracción de la actividad económica y de los que están persistiendo durante la recuperación. Estos problemas aparecieron, inicialmente, en las líneas que conectan los centros fabriles localizados en China y otras economías asiáticas con los grandes centros de consumo y producción de América del Norte y Europa, y se han extendido con posterioridad a otras líneas. Además, han afectado a una amplia gama de productos, con un impacto negativo en la capacidad de $D$ 
producción de la generalidad de los sectores manufactureros.

El comercio marítimo internacional se desarrolla principalmente a través de tres modalidades logísticas: el transporte de graneles líquidos, el de graneles sólidos y el de mercancías contenerizadas. Los requerimientos de infraestructuras portuarias (para el atraque, estiba y desestiba) y los tipos de contrato que rigen en estos mercados son muy distintos en cada una de estas modalidades. En los graneles, por lo general, un solo cargador contrata la capacidad total de un buque y paga en función de los días de duración del viaje, mientras que en los portacontenedores suele contratarse el viaje, compartiendo la capacidad del buque entre múltiples cargadores (Freire, González-Laxe y País, 2012).

Los buques portacontenedores pueden considerarse las «bestias de carga» de la economía globalizada. En las últimas décadas el transporte mediante este tipo de buques ha ganado peso en el conjunto del transporte marítimo. En el Gráfico 5 se observa cómo este tipo de naves ha pasado de representar el $1,5 \%$ del total del tonelaje de peso muerto en el año 1980 al $13,2 \%$ en 2021. La relevancia de este tipo de transporte para los productos manufacturados es, en realidad, mayor de la que sugiere este indicador y se apoya en ventajas como la flexibilidad que ofrece, la medida en que facilita el transporte intermodal o la mayor velocidad para las operaciones de carga y descarga. Presenta también limitaciones, como los mayores requerimientos de infraestructura portuaria, tanto en lo que se refiere a espacios logísticos como a maquinaria, y de equipamientos, incluyendo los propios contenedores.

El crecimiento del transporte contenerizado está asociado a dos fenómenos que se han reforzado mutuamente: el aumento del tamaño de los buques portacontenedores y la $\triangle$

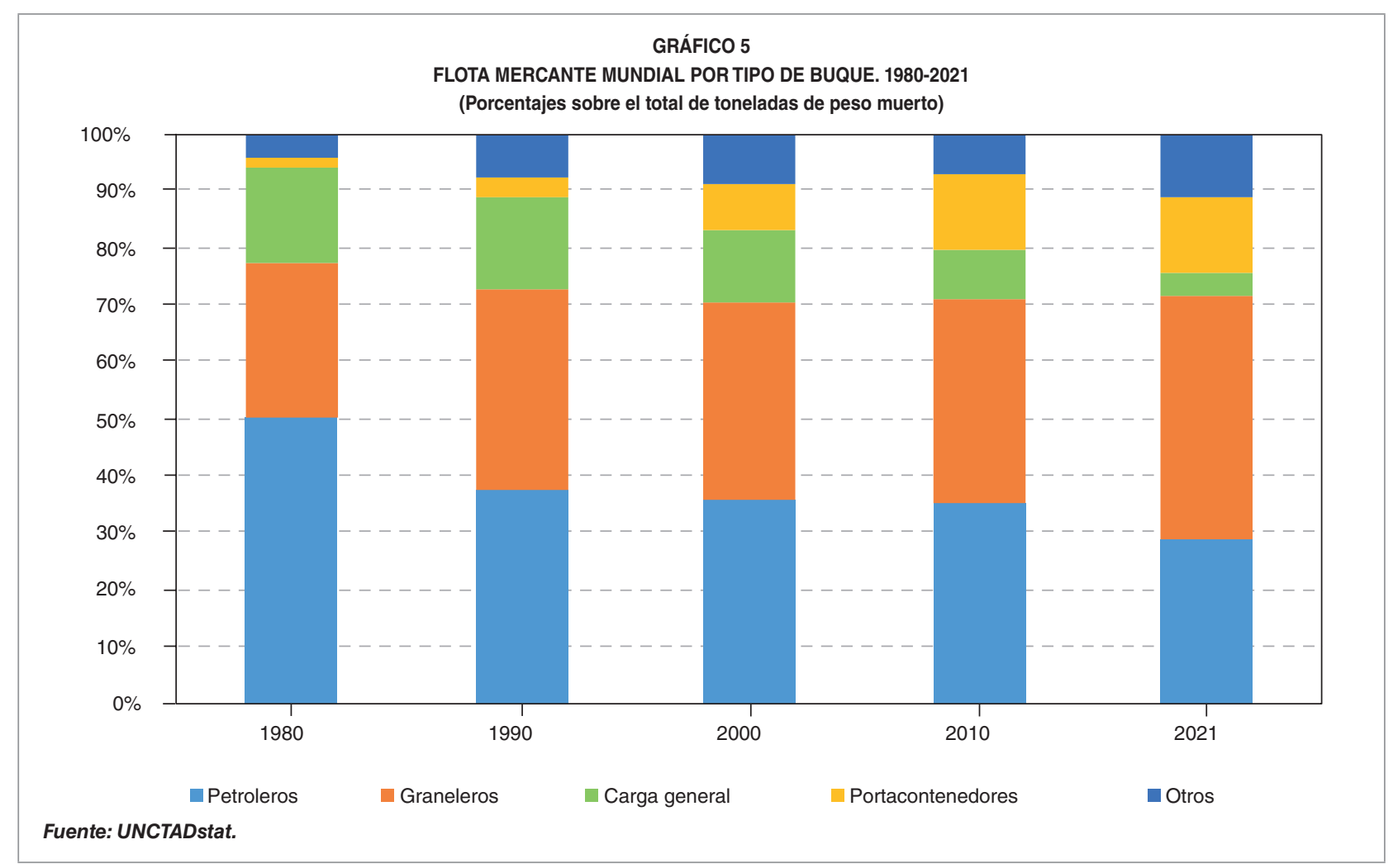


concentración del sector naviero a través, principalmente, de la creación de grandes alianzas internacionales. El aumento de tamaño de los buques genera economías de escala, pero supone también costes externos y aumenta los riesgos. Requiere la adaptación de las infraestructuras, especialmente las portuarias. Genera picos elevados en su utilización, así como en los requerimientos de transporte interno, para dar salida a la mercancía descargada en puertos. Supone una mayor concentración de riesgos y reduce la frecuencia y fiabilidad de cada línea marítima (Merk, Busquet \& Aronietis, 2015). La cooperación de las empresas navieras a través de grandes alianzas o consorcios globales facilita la compartición de buques, el alcance de economías de escala, reduciendo los costes unitarios, y permite un servicio más amplio. Sin estas alianzas probablemente no habría sido posible el desarrollo de los megabuques contenedores.

Esta evolución, no obstante, genera también preocupación por sus efectos en la resiliencia de las cadenas globales de suministro. El aumento de tamaño de los buques dificulta su asegurabilidad, aumenta los costes de un eventual rescate en caso de accidente y refuerza la concentración de la carga y los servicios conexos, reduciendo la capacidad de elección de los cargadores. Esta capacidad de elección se ve especialmente afectada porque, como se ha señalado, el aumento de tamaño de los buques portacontenedores se ha producido en paralelo con la intensificación de la integración de las grandes líneas navieras internacionales en tres grandes alianzas globales, lo que podría debilitar la competencia en el sector (Merk, Busquet \& Aronietis, 2015; Merk, Kirstein \& Salamitov, 2018).

La evolución de los precios de los fletes del transporte marítimo ha sido un reflejo de las limitaciones de la oferta para satisfacer la demanda.
Lo más significativo han sido los niveles récord que han alcanzado las tarifas de los fletes de transporte contenerizado. Los fletes de los graneles secos, que se habían reducido durante la primera mitad de 2020, se recuperaron en la segunda mitad del ejercicio y se han mantenido en niveles elevados en la primera parte de 2021. Esta evolución se asocia a las fluctuaciones en la demanda de materias primas, como los minerales de hierro, o productos agrarios, como los cereales. En el caso de los buques petroleros, los precios se mantienen en sus niveles históricamente más reducidos, ante una demanda debilitada por la pandemia y un exceso de estructural de oferta (UNCTAD, 2021c).

Los fletes que guardan relación más directa con los actuales problemas de suministro en la generalidad de la industria manufacturera son los del transporte contenerizado. Su escalada se inició en la segunda mitad de 2020, coincidiendo con la recuperación de la actividad económica y comercial internacional. En la primera parte de dicho año la gestión de la capacidad existente por parte de las empresas navieras, integradas en las grandes alianzas mundiales, evitó el colapso de los precios, a diferencia de lo que había ocurrido durante la crisis financiera de 2008-2009 (UNCTAD, 2021a). Sin embargo, en la segunda mitad del ejercicio y en el año 2021 se producen desajustes entre la oferta y la demanda de este tipo de buques que dan lugar a que los precios de sus fletes alcancen niveles récord, en especial en las rutas que conectan China con Europa y Estados Unidos (UNCTAD, 2021 b y 2021c). Estos desajustes están asociados a la rápida recuperación de la demanda, impulsada por la relajación de las restricciones impuestas para su contención y el avance de la vacunación, y a los cambios en los patrones de consumo, que fortalecieron de forma extraordinaria la demanda de algunas manufacturas, $D$ 
especialmente de bienes duraderos vinculados al equipamiento del hogar (Kataryniuk, del Río-Lopezosa y Sánchez-Carretero, 2021).

El índice FBX (Gráfico 6) refleja esta evolución. Este indicador agrega tarifas en mercados spot para contenedores equivalentes de 40 pies (FEU), como promedio ponderado de doce índices de rutas regionales, y se basa en datos comerciales de transportistas, transitarios y expedidores globales que utilizan la plataforma de gestión de tarifas de fletes de Freightos. Su evolución refleja un progresivo aumento del precio de los fletes desde mediados de 2020, coincidiendo con la reactivación económica, y una aceleración a partir de los primeros meses de 2021, cuando el comercio internacional ha recuperado sus niveles prepandemia y afloran los cuellos de botella generados durante la crisis. El precio medio semanal se multiplicó casi por 8 entre mayo de 2020 y septiembre de 2021 . Solo a partir de este mes se observa una cierta moderación.
En España, la Autoridad Portuaria de Valencia elabora el VCFI, un índice mensual que refleja la evolución de las tarifas del mercado de exportación de contenedores llenos por vía marítima desde el puerto de Valencia. Su evolución no ha sido muy distinta a la mostrada por el FBX, con un crecimiento constante desde el mínimo alcanzado en julio de 2020 (Gráfico 7). El análisis desagregado por rutas revela cómo el incremento de precios se inició en las rutas que unen el puerto con Asia, en los primeros meses de 2020, y ha afectado con posterioridad (desde finales de 2020) a las rutas hacia el Mediterráneo Occidental. Con información hasta octubre de 2021, el indicador no ha dado aún señales de moderación.

Como se ha señalado, el alza de precios de los fletes del transporte contenerizado responde a desajustes entre la oferta y la demanda vinculados con la pandemia, los cambios en la demanda global y en su composición, ajustes por el lado de la oferta y dificultades de $\square$

GRÁFICO 6

ÍNDICE GLOBAL DE FLETES DE CONTENEDORES FREIGHTOS-BALTIC (FBX) (Dólares por contenedor equivalente de 40 pies)

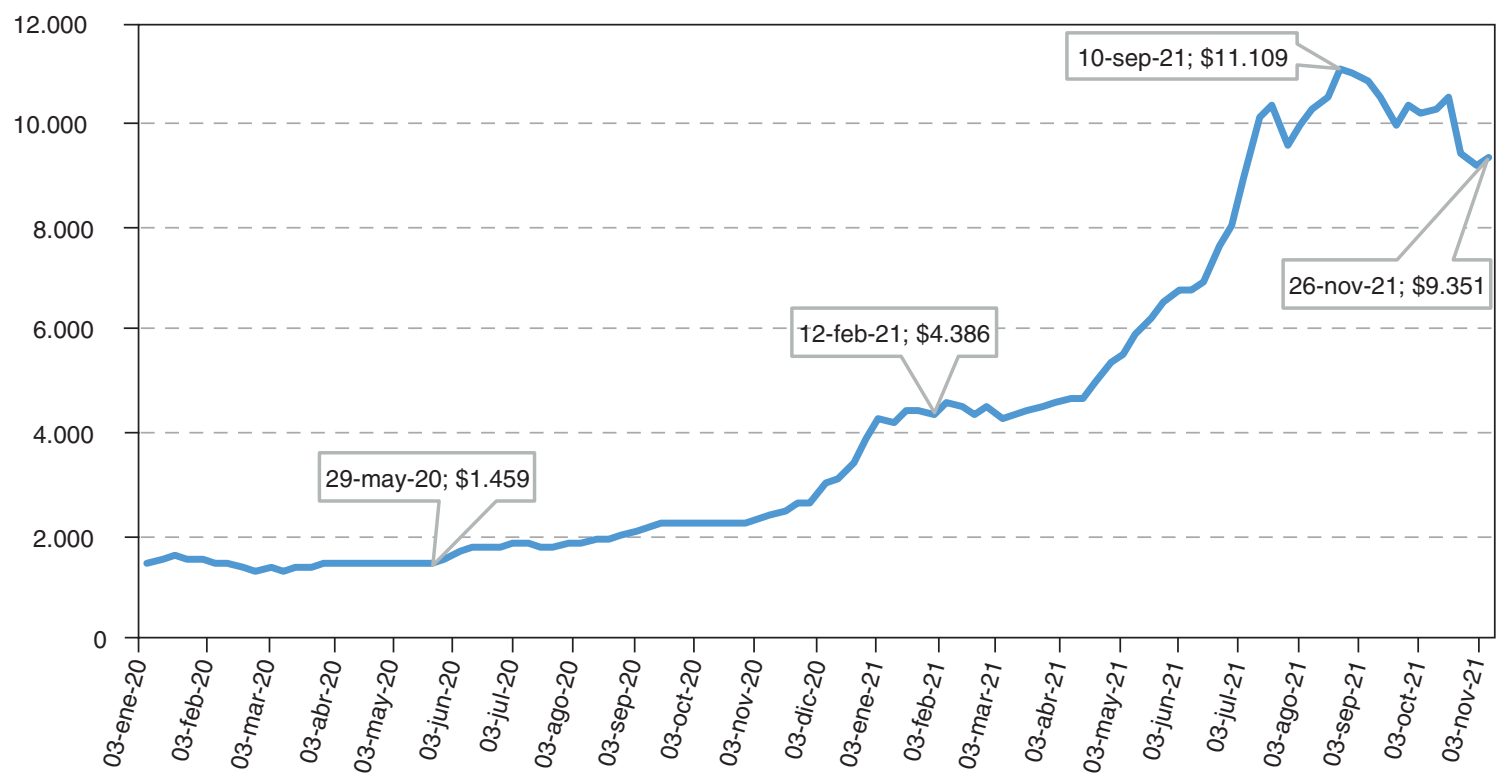

Fuente: Freightos Baltic Index. 


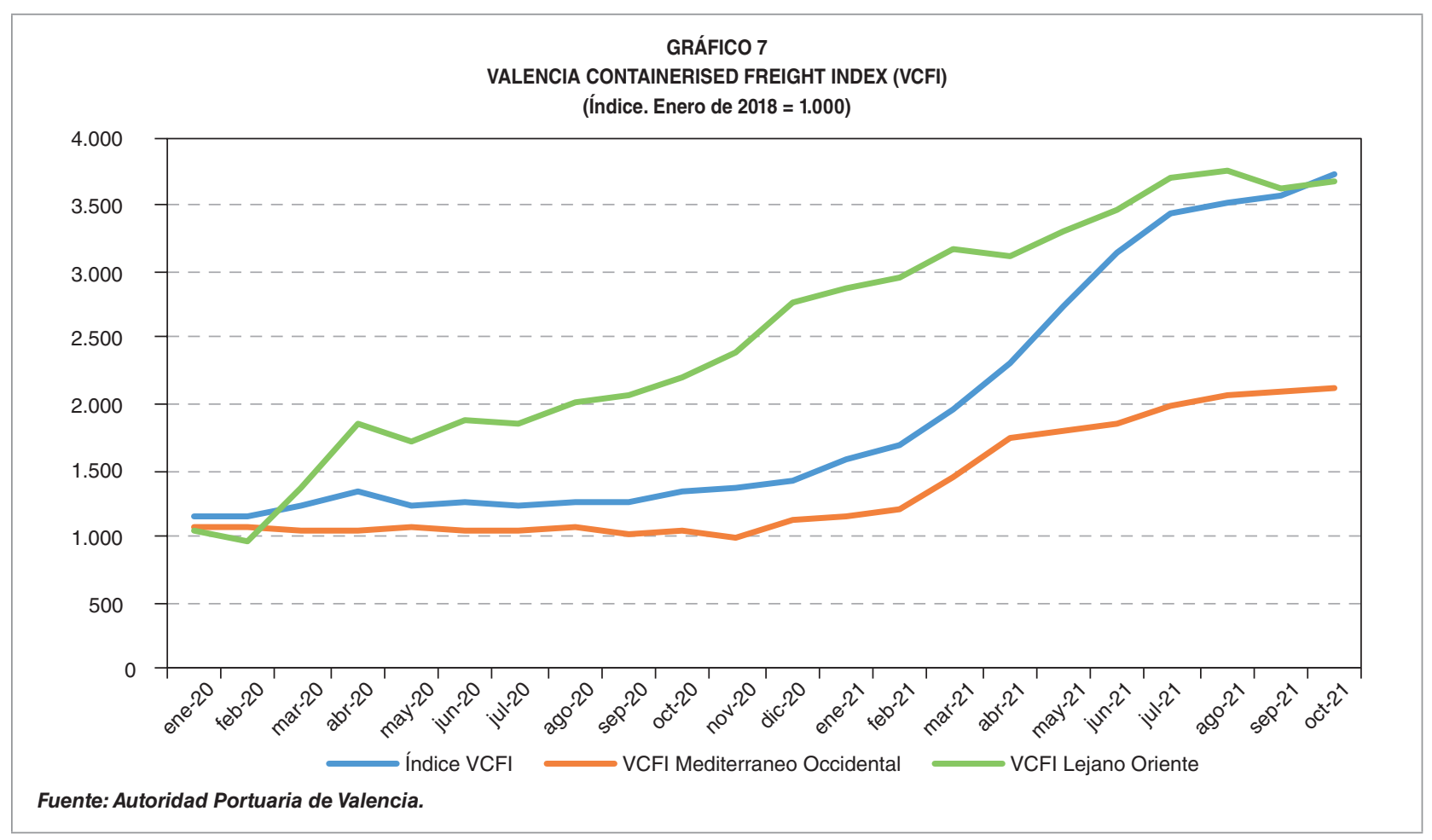

readaptación ante la recuperación. De forma más sistemática, puede destacarse la importancia de los siguientes factores:

- Cambios en las pautas de consumo: la pandemia tiene impacto en la composición de la demanda, lo que induce un cambio en el origen de las manufacturas demandadas, intensificando la dependencia de las rutas que conectan Asia con los grandes núcleos de demanda, donde restricciones, confinamientos y teletrabajo han reorientado las prioridades de consumo (Blyde \& Martincus, 2021). En consecuencia, se producen necesidades de relocalización de contenedores, desde las rutas con menor demanda a aquellas donde ha aumentado (Blyde \& Martincus, 2021; UNCTAD, 2021b).

- Reducción de la capacidad portuaria: los cierres temporales de puertos en China, la ralentización de las operaciones portuarias (vinculada con medidas de seguridad, escasez de mano de obra, etc.) y los cuellos de botella en el transporte terrestre con origen en los puertos dan lugar a una reducción de la capacidad operativa de los puertos de las principales rutas y a un aumento de los tiempos de espera de buques y de contenedores. Estos tiempos muertos suponen una reducción de la capacidad efectiva de transporte y un aumento del coste (UNCTAD, 2021b; Hald \& Coslugeanu, 2021).

- Reacción de las compañías navieras: las compañías navieras, integradas en grandes alianzas, respondieron a estas restricciones cancelando escalas, para ganar eficiencia, lo que genera problemas de desabastecimiento en algunos puertos (Hald \& Coslugeanu, 2021), de saturación de la capacidad en otros puertos y dificulta el necesario reposicionamiento de $\square$ 
los contenedores (UNCTAD, 2021b). A esto se añade el impacto de la pandemia sobre las tripulaciones de los buques que, en muchos casos, continúan con dificultades para acceder a las vacunas (UNCTAD, 2021c).

- Incertidumbre sobre la demanda: se esperaba que la pandemia redujera las necesidades de transporte marítimo; sin embargo, los cambios en las pautas de consumo y el recurso al comercio electrónico lo sostuvieron en cierta medida. A partir del tercer trimestre de 2020, la suavización de las medidas de contención, la recuperación de la actividad (a distintas velocidades) y el despliegue de planes de recuperación impulsan rápidamente el comercio. La oferta de transporte contenerizado (nuevos buques, nuevos contenedores y reposicionamiento de los existentes) y la capacidad de operación de los puertos no se recuperan al mismo ritmo (UNCTAD, 2021b y 2021c).

- Efectos dominó: aunque los problemas de escasez se registraran inicialmente en las rutas entre Asia y América del Norte o Europa, los efectos están siendo especialmente intensos en rutas como las que unen China con América del Sur o con África Occidental. Son rutas más largas (lo que implica más tiempo de uso de contenedores), con menor cargo de retorno (lo que implica más tiempo de contenedores en desuso), con menores frecuencias semanales (lo que conlleva mayor volatilidad de precios), y el papel inhibidor que, en estas áreas geográficas, puedan desempeñar las autoridades de competencia sobre el alza de precios es menos claro (UNCTAD, 2021b).
En el corto y medio plazo, las previsiones apuntan a un mantenimiento de precios elevados de los fletes del transporte contenerizado. Habitualmente hay un cierto desfase entre la demanda y la reacción de la oferta en el sector, ya que se requiere un tiempo para aportar nueva capacidad. En el caso actual, además, será necesario afrontar los problemas de restricciones en los puertos e instalaciones portuarias, lo que supone nuevas inversiones y soluciones en infraestructuras, digitalización y medidas de facilitación comercial (UNCTAD, 2021c).

Se espera, en consecuencia, que los precios elevados de los fletes se sostengan en el tiempo, lo que tendrá un impacto significativo en la evolución de costes y precios. La UNCTAD ha estimado el impacto del incremento de fletes sobre los precios, concluyendo que, si estos se mantienen en el nivel alcanzado en agosto de 2021, darán lugar a un aumento del $10,6 \%$ en los precios mundiales de importación y de un 1,5\% en los precios de consumo. El impacto sería más elevado en los precios de los productos más integrados en cadenas globales de valor y afectaría de forma asimétrica a las distintas economías, con una incidencia particularmente alta en los pequeños países insulares en desarrollo, muy dependientes del tráfico marítimo (UNCTAD, 2021c).

\section{Los desafíos a medio y largo plazo}

Los actuales problemas de abastecimiento de materias primas y productos manufacturados, ocasionados en parte por los cuellos de botella que han aflorado en el transporte marítimo de mercancías contenerizadas, se perciben esencialmente como transitorios. Aunque pueden ocasionar fricciones en el proceso de recuperación y aumentos temporales de los $D$ 
precios, no se espera que pongan en riesgo la reactivación económica.

No obstante, el análisis de estos cuellos de botella revela la importancia de factores que inciden en la cadena de suministro y que, hasta que la pandemia y la recuperación económica posterior los han hecho aflorar, habían pasado relativamente desapercibidos. La toma de conciencia sobre la importancia de estos factores tiene implicaciones, de medio y largo plazo, para la redefinición de las estrategias de las empresas, para la organización del transporte marítimo y para la reorientación de las políticas públicas, en particular, para las políticas comerciales en las que se centra este artículo.

Estos desafíos de medio y largo plazo responden a un cambio de paradigma, desde un mundo donde la búsqueda de la eficiencia es un objetivo de primacía casi absoluta a otro donde la gestión de riesgos y la construcción de resiliencia ganan protagonismo. En los siguientes párrafos se apuntan algunas reflexiones preliminares sobre las implicaciones de este cambio de paradigma.

\subsection{Adaptación de las estrategias empresariales}

En lo que se refiere a la estrategia de las empresas, la adaptación al nuevo paradigma implicaría, en primer lugar, identificar las vulnerabilidades. Esto supone mejorar el conocimiento integral de la cadena, incluyendo no solo los distintos niveles de proveedores de inputs, sino también las redes de distribución y nodos de transporte que emplean y establecer un mapa de riesgos. En segundo lugar, diversificar la base de suministradores, evitando la concentración geográfica de riesgos (particularmente, la dependencia de China). En tercer lugar, aumentar los inventarios de seguridad, para evitar que rupturas de inventarios paralicen la producción. Y, finalmente, aprovechar estos cambios organizativos para obtener mejoras de proceso (Shih, 2020). Se trata en todos los casos de estrategias costosas, que solo se justifican en un escenario en donde los riesgos de ruptura del suministro se perciban como especialmente relevantes.

En consecuencia, este tipo de remedios tradicionales (diversificación, flexibilidad y redundancia) no previenen necesariamente los riesgos derivados de «cisnes negros», cuya naturaleza imprevisible y mecanismos de transmisión ocultos requerirían una visión más amplia. En este sentido, Kouvelis aboga por repensar las cadenas de producción manufacturera y apostar por una automatización más flexible y una modularización de las tareas de procesamiento de forma que la producción pueda reaccionar a cambios en la composición de la demanda, como los observados durante la pandemia. Asimismo, defiende una mayor coordinación dentro de las industrias, con planificación de necesidades e inversiones conjuntas, especialmente, con relación a la gestión de recursos compartidos, como los de distribución o transporte o al empleo cualificado (Kouvelis, 2021).

\subsection{Tendencias a medio plazo en el transporte marítimo. El papel de la competencia}

En lo que se refiere al transporte marítimo, al margen de los actuales problemas coyunturales, deben tenerse presente los desafíos que enfrenta el sector a medio y largo plazo. Estos desafíos responden a tendencias preexistentes a la $\triangleright$ 
pandemia que, en algunos casos, se han visto aceleradas por ella.

Entre estas tendencias destacan, en primer lugar, la presión geopolítica, que apunta a una voluntad de menor dependencia de países geográfica y políticamente distantes. En segundo lugar, la reconfiguración de las estrategias empresariales y políticas públicas, para dotar de mayor resiliencia a las cadenas globales de valor, con implicaciones en términos de proximidad y diversificación de los suministros y de balance entre los beneficios del mantenimiento de inventarios y sus costes, pasando de un modelo de aprovisionamiento «justo a tiempo» (just in time) a un modelo «por si acaso» (just in case). En tercer lugar, la incorporación de tecnologías de la información y comunicaciones, no solo para mejorar la eficiencia, sino también para garantizar la continuidad, agilidad y seguridad del suministro. Aspectos como la difusión de estándares y mejora de la interoperabilidad, aumento del uso de la documentación electrónica en el comercio internacional, integración de los distintos eslabones de la cadena de suministro y preocupación por la seguridad ganarán importancia a medio plazo. En cuarto lugar, la dinámica del propio mercado naviero, que deberá ajustar sus inversiones y sus modos de operación a las lecciones aprendidas durante la pandemia. Finalmente, la adaptación del sector a la transición ecológica y al cambio climático, que tendrá efectos en varios ámbitos. En la industria naviera, como consumidor y como transportista de energía. En las infraestructuras de transporte marítimo (no solo los puertos, sino también otras, como los canales), por las inversiones necesarias para la mitigación de efectos del cambio climático y para la adaptación a los cambios que este pueda inducir en las rutas de transporte (UNCTAD, 2021c).
Otro aspecto que probablemente centrará la atención en los próximos años es el debate sobre los efectos de las grandes alianzas de transporte marítimo, en particular en el ámbito del transporte contenerizado. Se trata de una cuestión que ya en el pasado había generado opiniones contrapuestas con relación al saldo entre los efectos positivos que ofrecen, en términos de ganancias de eficiencia, compartición de riesgos y disminución de costes, y sus posibles riesgos, en términos de reducción de la competencia efectiva, concertación de conductas y eliminación de la capacidad de elección de los usuarios. El papel jugado por las alianzas en la crisis de la COVID-19 y el actual panorama de elevados costes de los fletes, probablemente, reavivan la polémica.

Estas alianzas o consorcios marítimos se apoyan normalmente en exenciones a las normas de defensa de la competencia que, teniendo presentes sus efectos positivos, crean un marco de seguridad jurídica para que empresas competidoras puedan colaborar entre sí. En el ámbito de la UE, el Reglamento (CE) 906/2009 (en adelante, CBER) establece las condiciones para eximir de la prohibición de llegar a acuerdos entre competidores que contienen los tratados comunitarios a determinadas categorías de acuerdos en el marco de los consorcios que prestan servicios de transporte marítimo internacional de línea regular desde o hacia uno o más puertos comunitarios. El CBER fue prorrogado en 2014, con efectos hasta 2020, y de nuevo en 2020, con vigencia hasta el 25 de abril de 2024.

Estas prórrogas no han estado exentas de debates. En el Recuadro 3 se resumen algunos de los argumentos, contrarios al mantenimiento de la exención por categorías o, al menos, a alguna de sus condiciones que se hicieron públicos previamente a la última prórroga, así como la valoración que entonces realizaron $\triangleright$ 


\section{RECUADRO 3 \\ ALIANZAS PARA EL TRANSPORTE DE CONTENEDORES Y COMPETENCIA}

La cooperación en alianzas globales cubre la utilización de buques, horarios de navegación, rutas, contenedores y uso conjunto de terminales. Existe un cierto nivel de acuerdo sobre el impacto positivo de las alianzas de primera generación, a mediados de los años noventa, que facilitaron la cooperación entre pequeñas navieras. Sin embargo, el efecto de las grandes alianzas actuales, en las que están integradas las mayores compañías, es más controvertido. Los tres principales consorcios globales, 2M, Ocean Alliance y The Alliance, representan en torno al $75 \%$ del transporte contenerizado.

Entre los argumentos críticos, destacan los siguientes (Merk, Kirstein \& Salamitov, 2018):

- Han generado un transporte marítimo más uniforme, limitando las posibilidades de diferenciación de las navieras.

- Han contribuido (en parte, al posibilitar la inversión en megabuques) a menores frecuencias de los servicios, reducción del número de conexiones directas entre puertos, baja fiabilidad de plazos y mayores tiempos de espera.

- Concentran el tráfico en determinadas redes portuarias y aumentan el riesgo de los puertos individuales ante un cambio de decisiones sobre las rutas.

- La alta concentración de poder de compra puede dar lugar a competencia destructiva entre los operadores de terminales y otros proveedores de servicios portuarios.

- Ejercen una enorme presión para la inversión en infraestructuras, con financiación pública, que puede no estar justificada.

- Aunque redujeron los costes de los fletes, en parte este ahorro se compensa con otros costes para los cargadores y con una reducción de la fiabilidad del servicio.

- Generan barreras de entrada en las principales rutas, y el intercambio de información entre los participantes en la alianza podría facilitar la colusión.

En contraste (Comisión Europea, 2019), en la evaluación para la prórroga del CBER se afirma que:

- Los consorcios reducen los costes mediante economías de escala, la racionalización de los servicios y una mejor utilización de los buques.

- La competencia entre los miembros del consorcio (competencia interna) y entre los distintos consorcios (competencia externa), dado que el CBER limita su cuota de mercado al $30 \%$, permite estimar que una parte equitativa de estos ahorros repercute en los clientes.

- Los acuerdos sujetos a las condiciones del CBER son indispensables para conseguir estas eficiencias y no existen medios menos restrictivos de la competencia para lograr iguales beneficios.

- Estos acuerdos no permiten eliminar una parte sustantiva de la competencia, debido a la competencia interna y externa que se mantiene.

El debate dista de estar cerrado. El Global Shippers' Forum ha lanzado recientes llamamientos a favor de la supresión de la exención por categorías a los acuerdos entre navieras (Baker, 2021). Si se optara por esta vía, los acuerdos quedarían plenamente sujetos a la normativa ordinaria de competencia de la UE, debiendo demostrar, caso a caso, que cumplen las condiciones para poder ser adoptados.

Fuente: elaboración propia a partir de Merk, Kirstein y Salamitov (2018), Comisión Europea (2019) y Baker (2021).

los servicios de la Comisión Europea. Como puede deducirse de la exposición recogida en anteriores epígrafes, es probable que este debate se intensifique en los próximos años. 


\subsection{Retos para la política comercial}

En el ámbito de las políticas públicas, la pandemia COVID-19 y su efecto disruptivo en la actividad económica han acentuado tendencias que estaban transformando la economía global. Entre ellas, la generalización de la incertidumbre ante los procesos de transformación, la reconfiguración de la globalización, el mayor peso del unilateralismo o la competencia por liderar la transformación digital.

En la UE estos desafíos se están afrontando mediante la acuñación del concepto de autonomía estratégica abierta. En el ámbito comercial este concepto se ha reflejado en una revisión de la política comercial (Comisión Europea, 2021a) que incorpora, entre otros principios, el de reforzar la resiliencia y las cadenas globales de valor.

Al igual que en el caso de las empresas, la respuesta a las disrupciones de las cadenas de suministro exige, por parte de los gestores de políticas públicas, una identificación de las vulnerabilidades que permita la adopción de prácticas o incentivos para reducirlas. Esta identificación de vulnerabilidades requiere el desarrollo de herramientas analíticas que permitan estudiar con un elevado nivel de detalle:

- El origen último de los suministros importados.

- La concentración geográfica de los suministros.

- La facilidad o dificultad para acceder a inputs sustitutivos desde el mercado doméstico o desde otros orígenes geográficos.

- Las vías marítima, terrestre o aérea y rutas de importación.

- El impacto, cuantitativo y cualitativo, que una interrupción en las importaciones de un producto puede tener en el conjunto de la economía.

Un análisis similar debería efectuarse para la vertiente exportadora, dado que disrupciones en los eslabones más próximos al cliente final pueden tener también impactos negativos en el resto de la cadena de valor.

En suma, se requiere un completo análisis de las cadenas de valor para poder construir un mapa de riesgos sobre el que diseñar acciones orientadas a sectores o industrias concretas. La Comisión Europea ya ha realizado un análisis de dependencia estratégica y capacidades (Comisión Europea, 2021b) que puede ser complementado con estudios nacionales.

\section{Conclusiones}

Como resultado de la COVID-19 se han producido cambios en la economía que han puesto de manifiesto debilidades en las cadenas internacionales de valor. La recuperación económica ha dado lugar a que afloren cuellos de botella que están produciendo dificultades para el abastecimiento de suministro que son generalizadas, al menos en los sectores manufactureros de la UE.

Aunque estos cuellos de botella son muy variados, algunos tienen un carácter más horizontal. Entre ellos, el transporte marítimo de mercancías mediante contenedores, que no se ha adaptado con suficiente flexibilidad a los cambios resultantes de la pandemia y de la recuperación económica. El resultado ha sido un crecimiento muy elevado del precio de los fletes, combinado con una reducción de la fiabilidad de las entregas y una extensión de plazos.

Las limitaciones de capacidad portuaria, las dificultades para reposicionar contenedores $\triangle$ 
y la falta de flexibilidad que ofrecen los megabuques portacontenedores pueden ser algunas de las razones que explican esta evolución. Se cuestiona también el impacto que tienen las grandes alianzas navieras en el desarrollo de la competencia en el sector.

Las empresas, el sector de transporte marítimo y las autoridades públicas deben adaptarse al cambio de paradigma que parece se está produciendo. Frente a un mundo donde lo primordial era la eficiencia, los objetivos relacionados con la identificación y gestión de riesgos ganan peso.

\section{Bibliografía}

Attinasi, M. G., Bobasu, A., y Gerinovics, R. (2021). ¿Qué factores están impulsando la reciente subida de los costes de transporte? BCE. Boletín Económico, (3/2021), 29-36. https://www.bde. es/f/webbde/SES/Secciones/Publicaciones/PublicacionesBCE/BoletinEconomicoBCE/2021/ Fich/bebce2103-2.pdf

Baker, J. (2021, June 14). Shippers renew call for block exemption to be removed. Lloyd's Loading List. https://www.lloydsloadinglist.com/freight-directory/adviceandinsight/Shippers-renew-callfor-block-exemption-to-be-removed/79280.htm\#. Yadgs9DMKUk

Blyde, J., \& Martincus, C. V. (2021). Why Are Shipping Costs Increasing? What US Import Data Tell Us. Más allá de las fronteras. Banco Interamericano de Desarrollo. https://blogs.iadb.org/integration-trade/en/why-are-shipping-costsincreasing-what-us-import-data-tell-us/

Comisión Europea. (2019). Evaluation of the Commission Regulation (EC) No 906/2009 of 28 September 2009 on the application of Article 81(3) of the Treaty to certain categories of agreements, decisions and concerted practices between liner shipping companies (consortia). SWD(2019) 412 final. https://ec.europa.eu/ competition/consultations/2018_consortia/1_ en_dts_evaluation.pdf

Comisión Europea. (2021a). Comunicación (COM(2021)66 final), de 18 de febrero de 2021, de la Comisión al Parlamento Europeo, al Consejo, al Comité Económico y Social Europeo y al Comité de las Regiones. Revisión de la política comercial - Una política comercial abierta, sostenible y firme. https://eur-lex.europa.eu/legalcontent/ES/TXT/?uri=CELEX:52021DC0066

Comisión Europea. (2021b). Strategic dependencies and capacities accompanying the Communication from the Commission to the European Parliament, the Council, the European Economic and Social Committee and the Committee of the Regions. Updating the 2020 New Industrial Strategy: Building a stronger Single Market for Europe's recovery. SWD(2021) 352 final. https://eurlex.europa.eu/legal-content/FR/TXT/?uri= CELEX:52021SC0352

Freire Seonae, M. J., González-Laxe, F. I., y País Montes, C. (2012). Análisis de los fletes en el transporte marítimo internacional. En La Economía del Transporte Marítimo y los Puertos. Papeles de Economía Española, (131), 48-63. https:// www.funcas.es/wp-content/uploads/Migracion/ Publicaciones/PDF/1781.pdf

Hald, K. S., \& Coslugeanu, P. (2021). The Preliminary Supply Chain Lessons of the COVID-19 Disruption: What Is the Role of Digital Technologies? Operations Management Research, 1-16. https://doi.org/10.1007/s12063-021-00207-x

Kataryniuk, I., del Río Lopezosa, A., y Sánchez Carretero, C. (2021). Los cuellos de botella del sector manufacturero de la zona del euro. Boletín Económico del Banco de España, (3), 30-34. https://www.bde.es/f/webbde/SES/Secciones/ Publicaciones/InformesBoletinesRevistas/BoletinEconomico/Informe \%20trimestral/21/Recuadros/Fich/be2103-it-Rec3.pdf

Kouvelis, P. (2021). Paradoxes and mysteries in virus-infected supply chains: Hidden bottlenecks, changing consumer behaviors, and other nonusual suspects. Business Horizons, 64(6). https://doi.org/10.1016/j.bushor.2021.06.003 $\square$ 
KPMG. (2021). CEO Outlook. Adaptación, personas y futuro. https://assets.kpmg/content/dam/kpmg/ es/pdf/2021/09/2021-ceo-outlook-espana.pdf

Merk, O., Busquet, B., \& Aronietis, R. (2015). The Impact of Mega-Ships. Organization for Economic Cooperation and Development. Case-Specific Policy Analysis. International Transport Forum (OECD/TIF). https://www.itf-oecd.org/impact-megaships

Merk, O., Kirstein, L., \& Salamitov, F. (2018). The Impact of Alliances in Container Shipping. Organization for Economic Cooperation and Development. Case-Specific Policy Analysis. International Transport Forum (OECD/TIF). https://www.itfoecd.org/sites/default/files/docs/impact-alliances-container-shipping.pdf

Reglamento (CE) N.9 906/2009, de la Comisión, de 28 de septiembre de 2009 sobre la aplicación del artículo 81, apartado 3, del Tratado a determinadas categorías de acuerdos, decisiones y prácticas concertadas entre compañías de transporte marítimo de línea regular (consorcios). Diario Oficial de la Unión Europea, L 256, de 29 de septiembre de 2009, pp. 31 a 34. https://eur-lex.europa.eu/legal-content/ES/TXT/ PDF/?uri=CELEX:32009R0906\&from=EN

Shih, W. C. (2020). Global Supply Chains in a Post-Pandemic World. Harvard Business Review, 98(5), 82-89. https://hbr.org/2020/09/globalsupply-chains-in-a-post-pandemic-world

Taleb, N. N., (2007). The Black Swan: The Impact of the Highly Improbable. Penguin.

UNCTAD. (2021a). Covid-19 and Maritime Transport: Impact and Responses. Transport and Trade Facilitation Series, (15). https://unctad.org/es/ node/28939

UNCTAD. (2021b). Container Shipping in Times of COVID-19: Why Freight Rates Have Surged, and Implications for Policy Makers. Policy Brief, (84). https://unctad.org/es/node/32652

UNCTAD. (2021c). Review of Maritime Transport 2021.https://unctad.org/system/files/official-document/rmt2021_en_0.pdf 
